\title{
O CONHECIMENTO EM ENFERMAGEM PEDIÁTRICA: LIVROS EDITADOS NO BRASIL DE 1916 A 1988
}

\author{
Semiramis Melani Melo Rocha* \\ Carmen Gracinda Silvan Scochi** \\ Regina Aparecida Garcia de Lima**
}

Para a apreensão do conhecimento em enfermagem pediátrica no Brasil fez-se um levantamento em uma obra de referencia bibliográfica de enfermagem brasileira. A postura teórica metodológica adotada concebe a enfermagem em uma perspectiva histórica, parte de um processo coletivo de trabalho e o saber como instrumental que permite a transformação do objeto no produto desejado, de acordo com a finalidade do trabalho, imprimindo racionalidade ao processo. Foram encontrados quarenta títulos sobre assistência à criança (8\%) em um total de quinhentos e quatro, proporção considerada pequena. A produção foi classificada em prescritiva e analítica. Prescritiva refere-se aos textos que normalizam o trabalho com vistas a sua racionalidade e produtividade. Os analíticos abrem a possibilidade de diversificar o cuidado de enfermagem atendendo com alguma especificidade a clientela, redimensionando a finalidade do trabalho de enfermagem.

UNITERMOS: Enfermagem pediátrica, conhecimento em enfermagem pediátrica.

\section{Introdução}

O objeto deste estudo é a Enfermagem Pediátrica. O objeto da Enfermagem Pediátrica ou de assistência de enfermagem a criança não está imediatamente dado, mas ideado, como é próprio dos produtos da cultura. As manifestações do pensamento sobre assistência a,

\footnotetext{
*Professor Associado da Escola de Enfermagem de Ribeirão Preto da Universidade de São Paulo.
}

**Professor Assistente da Escola de Enfermagem de Ribeirão Preto da Universidade de São Paulo. 
criança não vieram a existência sem causa, isto e, não se tratam de opiniões contingentes e conjeturais, mas de idéias que devem ter entre si conexão racional.

Os homens não criam um conhecimento ao acaso; é sempre um determinado conhecimento que surge no seio de um povo e a determinação é idêntica a que se apodera de todas as demais manifestações deste povo; está em íntima relação com elas e delas constitui o fundamento. A forma particular de um conhecimento e sincrônica com a constituição particular de um povo, suas instituições, forma de governo, moralidade, vida social, religião e com todas as circunstâncias externas ${ }^{7}$.

O conhecimento e um dos instrumentos, pelo qual o homem apreende seu objeto de trabalho. Através dos órgãos dos sentidos, o homem apreende a realidade objetiva e a representa mentalmente. As representações mentais passam por um processo de identificação, associação e relacionamento; através deste processo vão se elaborando conceitos. A linguagem é a forma de expressão dos conceitos que, para serem válidos, devem submeter-se à lógica formal ou dialéticat ${ }^{4}$.

O conjunto de trabalhos institucionalizados que compõem o "Setor Saúde" nas sociedades capitalistas ocidentais deriva grande parte de sua legitimação social do fato de justificar suas técnicas de intervenção como aplicações diretas e imediatas do saber científico sobre o corpo humano e sua doença. Tendencialmente, todos os outros trabalhos que compõem juntos o trabalho social nas sociedades modernas e complexas se propõem a serem, se não científicos, pelo menos aplicações imediatas da ciência. Entretanto, no plano das representações sociais, feitas pelos próprios agentes do trabalho em saúde, bem como pela sociedade em geral, imagina-se que o trabalho em saúde seja "mais cientifico" do que outros, quando não, que seja imediatamente científico ${ }^{10}$.

Em sua forma desenvolvida no Ocidente, a partir de fins do século XVII, o trabalho em saúde tem no médico o trabalhador central e paradigmático. Este vem acumulando as funções de trabalho e de investigação, embora parte deles se restrinja ao trabalho de produção de serviços. Assim, o médico-cientista foi construindo seu objeto do conhecimento e ao mesmo tempo conhecendo seu objeto de trabalho.

"Essa construção, de modo coerente com a vinculação da Medicina a racionalidade científica moderna, constitui no erguimento de um imenso edifício baseado no pressuposto de que "a doença" e uma alteração morfofuncional do corpo humano reduzido as suas dimensões biológicas. As ciências fundamentais então construídas são a Anatomia, a Fisiologia e a Patologia, por um lado, e a Farmacologia, por outro, isto é, são as ciências que embasam os procedimentos singulares da arte do médico de diagnosticar e prescrever ${ }^{\prime \prime 10}$.

A enfermagem moderna nasce no desdobramento do ato médico em tarefas suplementares e de infra-estrutura e sua institucionalização tem como marco inicial o trabalho de Florence Nightingale. O desenvolvimento de uma ciência correspondente ao conjunto do trabalho de enfermagem, no mesmo sentido em que as ciências apontadas por MENDES GONÇALVES ${ }^{10}$, acima citadas, correspondem ao trabalho médico, é uma 
preocupação já manifestada par Nightingale. Dentre os trabalhos por ela escritos, o mais conhecido, recentemente traduzido para o português "Notas sobre Enfermagem", propõe noções distintas dos conhecimentos médicos que deveriam ser conhecidas por todos que pretendessem exercer a enfermagem ${ }^{11}$.

Alguns autores têm se dedicado especificamente ao estudo do saber em enfermagem. ALMEIDA \& ROCHA ${ }^{2}$ em uma perspectiva histórica e considerando o saber como instrumental para a realização de um trabalho, identificam três expressões do saber em enfermagem: as técnicas, os princípios científicos e as teorias de enfermagem. As técnicas começam a ser organizadas no final do século XIX e têm seu pleno desenvolvimento até meados de 1950. São uma resposta imediata e significativa a organização do trabalho hospitalar, nas primeiras décadas do século, nos Estados Unidos. Após a produção das técnicas básicas de enfermagem, surgem as técnicas em áreas especificas, acompanhando a especialização médica. Dentre suas finalidades, a considerada mais importante é proporcionar conforto e segurança ao paciente. Em sua dimensão histórica, as técnicas tiveram a finalidade de dimensionar, disciplinar e hierarquizar os agentes de enfermagem no espaço social hospitalar, com o objetivo principal de auxiliar o trabalho médico.

Na década de 50 surge a preocupação, encabeçada por educadores de enfermagem norte-americanos, em organizar os princípios científicos que devem nortear a prática. Procura-se agregar as técnicas de enfermagem, que não possuíam uma teoria para fundamentá-las; inicialmente, conhecimentos de biologia, fisiologia e prática médica, ampliando esta fundamentação com a contribuição do atendimento biopsicossocial do paciente e possibilitando a dimensão intelectual do trabalho de enfermagem.

$\mathrm{Na}$ década de 70, enfermeiros norte-americanos começam a trabalhar na construção de um corpo de conhecimentos específicos da enfermagem, procurando sua autonomia e especificidade. É o saber da enfermagem expresso através do que se convencionou chamar de teorias de enfermagem. Para ALMEIDA \& ROCHA ${ }^{2}$, parece ser uma proposta voltada mais para as dimensões científicas sem contemplar a dimensão social da prática. Voltado para um projeto ideológico de cientificismo e autonomia da enfermagem, não produz um saber crítico que considere as contradições tanto no interior do trabalho de enfermagem como as relacionadas à estrutura social.

No Brasil HORTA \& CASTELLANOS ${ }^{8}$, partindo das teorias norte-americanas e de uma perspectiva que conceitua a enfermagem como ciência, desenvolvem um corpo de conhecimentos para possibilitar a utilização da metodologia cientifica nas ações de enfermagem. Posteriormente, dentro desta mesma perspectiva, outros trabalhos vêm se somar a este.

Tem-se, portanto, pelo menos duas posições expressas sobre a enfermagem; a primeira, a considera uma prática inserida na sociedade e como tal, historicamente estruturada, estabelecendo relações sociais com todos os outros tipos de trabalho e guardando sua especificidade dentro de uma autonomia relativa ${ }^{3}$. A segunda, a considera uma ciência formal 
ou positiva, acumulando um corpo de conhecimentos e técnicas e que hoje desenvolve teorias relacionadas entre si, procurando explicar e predizer os fatos ${ }^{8}$.

Assumindo a primeira posição, isto e, entendendo a enfermagem como uma prática social, pretende-se neste trabalho, compreender a enfermagem pediátrica em suas relações com o social. Os instrumentos entre eles o conhecimento sobre o objeto, exprimem não s6 as soluções técnicas adequadas ao processo de trabalho, mas, sobretudo indicam como os homens se organizam na produção e reprodução de sua existência e as relações sociais que estabelecem entre si.

Atualmente os enfermeiros vêm questionando as relações entre os agentes do processo de trabalho em saúde, a autonomia profissional do próprio enfermeiro, a hierarquia entre as diferentes categorias de enfermagem, o impacto das pesquisas em enfermagem na assistência e as características de seu objeto de trabalho.

O conhecimento é um dos momentos do processo de trabalho, determinado historicamente pelas características do objeto e pela finalidade do trabalho. Seu estudo permite reflexões sobre os outros momentos do processo de trabalho, o objeto, seus agentes, a finalidade e as relações entre os agentes. Não se pretende aqui estabelecer relações entre a teoria e a prática, pois a fonte de dados utilizada limita-se à produção de conhecimentos escrita e divulgada.

O problema a ser investigado e identificar, no conhecimento existente sobre enfermagem pediátrica, o objeto de que trata, o contexto onde se situa este objeto, os instrumentos utilizados para apreender e transformar este objeto e quais as finalidades do trabalho na assistência de enfermagem à criança. Diante da complexidade do problema e de uma série de limitações inerentes a uma pesquisa, foram feitas aproximações aos momentos do processo de trabalho, acima citadas, ora mais discutidas, ora mais superficiais. As considerações e análises sobre os dados levantados são baseadas na experiência profissional das autoras.

A postura teórico-metodológica aqui adotada concebe a enfermagem como parte de um processo coletivo de trabalho, cujas finalidades são: o controle da doença na sociedade a nível coletivo e a recuperação da força de trabalho individual.

\section{A literatura sobre enfermagem pediátrica no período de 1916 a 1988: fontes de informação, critérios de seleção e análise}

Para a apreensão do conhecimento em enfermagem pediátrica divulgado no Brasil, utilizou-se a obra de referência CASTRO, leda Barreira \& BATISTA, Suely de Souza. Livros de Enfermagem: Brasil (1916-1988). Rio de Janeiro, ABEn/CEPEn e UFRJ., 1989. 149 p. Esta referência bibliográfica histórica, registra títulos sobre enfermagem editados no Brasil de 
autores nacionais ou estrangeiros, enfermeiros ou não, indicando sempre que possível sua primeira edição.

Baseia-se em uma pesquisa sistemática as referências bibliográficas dos artigos da REBEn, dos Anais dos Congressos Brasileiros de Enfermagem (1978-1986), dos Anais dos Seminários Nacionais de Pesquisa em Enfermagem (1977-1986) e em uma consulta a catálogos de editoras, distribuidoras, a acervos de bibliotecas públicas, particulares, bem como a noventa e oito Escolas de Enfermagem, a Sede, as vinte e duas Seções e as vinte e três Regionais da Associação Brasileira de Enfermagem. Também Foram consultadas as bibliotecas da Fundação Serviços de Saúde Pública (FSESP), Campanha Nacional contra a Tuberculose/CNCT e a BIREME. Apresenta um total de quinhentos e quatro títulos levantados e catalogados. Incluem-se neste levantamento, livros, Folhetos e publicações semi-artesanais, devido a sua importância histórico-documental ou técnico-científica.

Realizou-se uma primeira consulta a "Classificação das obras por áreas temáticas. Onde foram selecionadas, pelo título, as que se referiam a assistência de enfermagem a criança, enfermagem materno-infantil, puericultura e serviços de pediatria. A seguir, recorreu-se ao índice cronológico para conferência dos títulos levantados.

No Quadro 1 estão apresentados os títulos selecionados, editores, tradutores, autores, data e local. No Quadro 2 sintetiza-se o levantamento quantitativo por décadas, separando-se os autores nacionais dos estrangeiros traduzidos. Observam-se quarenta publicações sobre assistência a criança, representado $8 \%$ em um total de quinhentos e quatro, proporção considerada pequena.

Entre 1930 e 1950 foram editados dois manuais sobre organização e funcionamento de lactários e três livros sobre puericultura (Quadro 1 e 2).

Até 1970, o número de publicações é insignificante (12,5\%) aumentando a partir daí a freqüência, especialmente no período de 1980 a 1988 (60\%). Esta maior concentração de publicações nas décadas de 70 a 80, provavelmente, decorre de dois fatos: os cursos de enfermagem foram elevados a nível superior a partir dos anos 60 e nos anos 70 instala-se a pós-graduação em enfermagem no Brasil. Conseqüentemente, aumenta a produção intelectual própria dos enfermeiros, para atender as necessidades correspondentes à parte do processo de trabalho que executam nas instituições de saúde e a formação de recursos humanos. 


\section{QUADRO 1 - LIVROS DE ENFERMAGEM SOBRE ASSISTÊNCIA À CRIANÇA, EDITADOS NO BRASIL DE AUTORES NACIONAIS OU ESTRANGEIROS, ENFERMEIROS OU NÃO. 1916-1988.}

\begin{tabular}{|c|c|c|c|c|c|}
\hline ANO & TÍTULO & EDITORA & TRADUTOR & AUTOR & LOCAL \\
\hline 1930 & $\begin{array}{l}\text { Breviário das mães e das } \\
\text { enfermeiras - noções de } \\
\text { higiene natal e infantil }\end{array}$ & - & $\begin{array}{l}\text { Jorge Sant'Ana } \\
\text { Matinho da } \\
\text { Rocha Jr. José } \\
\text { Martinho da } \\
\text { Rocha }\end{array}$ & $\begin{array}{l}\text { Birk, W. \& } \\
\text { Mayer, A. }\end{array}$ & $\begin{array}{l}\text { Rio de } \\
\text { janeiro }\end{array}$ \\
\hline 1934 & $\begin{array}{l}\text { Noções de alimentação } \\
\text { de alimentação infantil: } \\
\text { técnica de preparo de } \\
\text { alimentos }\end{array}$ & - & - & $\begin{array}{l}\text { Roza, Margarida } \\
\text { Irma dos Passos }\end{array}$ & - \\
\hline 1946 & $\begin{array}{l}\text { Instruções para } \\
\text { organização e } \\
\text { funcionamento de } \\
\text { lactários nos consultórios } \\
\text { de higiene infantil nas } \\
\text { Unidades Sanitárias. }\end{array}$ & $\begin{array}{l}\text { (Ministério da } \\
\text { Educação e } \\
\text { Saúde/Divisão de } \\
\text { Organização } \\
\text { Sanitária - } \\
\text { Folheto) } \\
\end{array}$ & - & $\begin{array}{l}\text { Lima, Izaura } \\
\text { Barbosa }\end{array}$ & $\begin{array}{l}\text { Rio de } \\
\text { Janeiro }\end{array}$ \\
\hline 1950 & $\begin{array}{l}\text { Manual de organização e } \\
\text { funcionamento de } \\
\text { lactário }\end{array}$ & $\begin{array}{l}\text { (Ministério da } \\
\text { Educação e } \\
\text { Saúde/Divisão de } \\
\text { Organização } \\
\text { Sanitária - } \\
\text { Folheto) }\end{array}$ & - & $\begin{array}{l}\text { Lima, Izaura } \\
\text { Barbosa }\end{array}$ & $\begin{array}{l}\text { Rio de } \\
\text { Janeiro }\end{array}$ \\
\hline 1954 & $\begin{array}{l}\text { Puericultura para } \\
\text { enfermeira }\end{array}$ & Irmãos Di Giorgio & - & Rangel, Mário & $\begin{array}{l}\text { Rio de } \\
\text { Janeiro }\end{array}$ \\
\hline 1970 & $\begin{array}{l}\text { Seminário sobre } \\
\text { assistência de } \\
\text { enfermagem materno- } \\
\text { infantil na Macro-Região } \\
\text { Centro Oeste. }\end{array}$ & - & - & $\begin{array}{l}\text { (MS/OPAS - } \\
\text { OMS) }\end{array}$ & Brasília \\
\hline 1971 & $\begin{array}{l}\text { Elementos básicos de } \\
\text { assistência de } \\
\text { enfermagem pediátrica }\end{array}$ & - & - & $\begin{array}{l}\text { Rocha, Dulce } \\
\text { Neves da }\end{array}$ & $\begin{array}{l}\text { Rio de } \\
\text { Janeiro }\end{array}$ \\
\hline 1972 & $\begin{array}{l}\text { Guias de estudo de } \\
\text { enfermagem pediátrica. }\end{array}$ & ABEn & - & Moraes, Esther & São Paulo \\
\hline 1972 & Enfermagem pediátrica & $\begin{array}{l}\text { Expressão e } \\
\text { Cultura/MEC }\end{array}$ & - & $\begin{array}{l}\text { Rocha, Dulce } \\
\text { Neves da \& Pain, } \\
\text { Lygia }\end{array}$ & Brasília \\
\hline 1976 & Enfermagem pediátrica & Interamericana & \begin{tabular}{|l} 
Raymundo \\
Martagão \\
Gesteira et alii
\end{tabular} & $\begin{array}{l}\text { Waechter, } \\
\text { Eugênia H. \& } \\
\text { Blake, Florênce G. }\end{array}$ & $\begin{array}{l}\text { Rio de } \\
\text { Janeiro }\end{array}$ \\
\hline
\end{tabular}




\begin{tabular}{|c|c|c|c|c|c|}
\hline 1977 & $\begin{array}{l}\text { Diagnóstico na } \\
\text { Enfermagem pediátrica }\end{array}$ & $\begin{array}{l}\text { Organização } \\
\text { Andrei }\end{array}$ & $\begin{array}{l}\text { Joaquim } \\
\text { Clemente de } \\
\text { Almeida Moura }\end{array}$ & $\begin{array}{l}\text { Alexander, Mary } \\
\text { M. \& Brown, Marie } \\
\text { Scott }\end{array}$ & São Paulo \\
\hline 1978 & Enfermeira pediatra & Sarvier & - & $\begin{array}{l}\text { Augusto, Marianna } \\
\& \text { Noda, Massae }\end{array}$ & São Paulo \\
\hline 1978 & $\begin{array}{l}\text { A enfermagem de Saúde } \\
\text { Pública na assistência } \\
\text { materno-infantil }\end{array}$ & Juerp & - & $\begin{array}{l}\text { Dantas, Inês } \\
\text { Pereira }\end{array}$ & $\begin{array}{l}\text { Rio de } \\
\text { Janeiro }\end{array}$ \\
\hline 1978 & $\begin{array}{l}\text { Reunião de enfermagem } \\
\text { materno-infantil da Bahia }\end{array}$ & ABEn & - & - & Salvador \\
\hline 1978 & $\begin{array}{l}\text { Enfermagem materno- } \\
\text { infantil }\end{array}$ & Fernando Azevedo & - & $\begin{array}{l}\text { Santos, Diva } \\
\text { Brandão dos }\end{array}$ & $\begin{array}{l}\text { Rio de } \\
\text { Janeiro }\end{array}$ \\
\hline 1980 & $\begin{array}{l}\text { Pediatria ambulatório } \\
\text { para enfermeiras }\end{array}$ & $\begin{array}{l}\text { Organização } \\
\text { Andrei }\end{array}$ & $\begin{array}{l}\text { Zilda Barbosa } \\
\text { Antony }\end{array}$ & $\begin{array}{l}\text { Brown, Marie } \\
\text { Scott \& Murphy, } \\
\text { Mary Alexander }\end{array}$ & São Paulo \\
\hline 1981 & $\begin{array}{l}\text { Manual de procedimento } \\
\text { para auxiliares de } \\
\text { enfermagem em } \\
\text { pediatria. }\end{array}$ & $\begin{array}{l}\text { União Social } \\
\text { Camiliana/CED AS }\end{array}$ & - & Russo, Ruth Gentil & São Paulo \\
\hline 1981 & $\begin{array}{l}\text { Caderno de enfermagem: } \\
\text { pediatria }\end{array}$ & Masson do Brasil & - & Russo, Ruth Gentil & São Paulo \\
\hline 1982 & $\begin{array}{l}\text { Assistência de } \\
\text { enfermagem ao recém- } \\
\text { nascido o alojamento } \\
\text { conjunto. }\end{array}$ & $\begin{array}{l}\text { Imprensa da } \\
\text { U.F.R.N. }\end{array}$ & - & $\begin{array}{l}\text { Araújo, Mariluce } \\
\text { Oliveira de }\end{array}$ & Natal \\
\hline 1982 & $\begin{array}{l}\text { Alojamento conjunto } \\
\text { mãe-filho e o enfermeiro: } \\
\text { incentivo à } \\
\text { amamentação. }\end{array}$ & $\begin{array}{l}\text { Imprensa } \\
\text { Universitária }\end{array}$ & - & Campestri, Selma & Curitiba \\
\hline 1982 & $\begin{array}{l}\text { Alimentação da criança } \\
\text { no primeiro ano de vida; } \\
\text { problemas nutricionais do } \\
\text { lactente. }\end{array}$ & $\begin{array}{l}\text { Universitária da } \\
\text { U.F.R.N. }\end{array}$ & - & $\begin{array}{l}\text { Melo, Milfred } \\
\text { Negreiros } \\
\text { Bezerra de }\end{array}$ & Natal \\
\hline 1982 & $\begin{array}{l}\text { Enfermagem } \\
\text { neonatológica }\end{array}$ & U.F.R.G.S. & - & $\begin{array}{l}\text { Pizatto, Mariana } \\
\text { Geraldi \& Da } \\
\text { Poian, Vera } \\
\text { Regina L. }\end{array}$ & $\begin{array}{l}\text { Porto } \\
\text { Alegre }\end{array}$ \\
\hline 1982 & $\begin{array}{l}\text { Tarefas individuais } \\
\text { programadas sobre } \\
\text { enfermagem } \\
\text { neonatológica. }\end{array}$ & U.F.R.G.S. & - & $\begin{array}{l}\text { Pizatto, Mariana } \\
\text { Geraldi \& Da } \\
\text { Poian, Vera } \\
\text { Regina L. }\end{array}$ & $\begin{array}{l}\text { Porto } \\
\text { Alegre }\end{array}$ \\
\hline
\end{tabular}




\begin{tabular}{|c|c|c|c|c|c|}
\hline 1982 & $\begin{array}{l}\text { O simbolismo da afeição } \\
\text { para a criança } \\
\text { hospitalizada }\end{array}$ & Gráfica Star & - & $\begin{array}{l}\text { Pontes, Cleide } \\
\text { Maria }\end{array}$ & Recife \\
\hline 1983 & $\begin{array}{l}\text { Assistência de } \\
\text { enfermagem ao recém- } \\
\text { nascido no berçário e ao } \\
\text { binômio mãe e filho no } \\
\text { alojamento conjunto do } \\
\text { Hospital das Clínicas da } \\
\text { Faculdade de Medicina } \\
\text { da U.F.M.G. }\end{array}$ & $\begin{array}{l}\text { Imprensa da } \\
\text { U.F.M.G. }\end{array}$ & - & $\begin{array}{l}\text { Costa, Adelaide } \\
\text { Maria et alli }\end{array}$ & $\begin{array}{l}\text { Belo } \\
\text { Horizonte }\end{array}$ \\
\hline 1983 & $\begin{array}{l}\text { Enfermagem obstétrica e } \\
\text { neonatal para técnicos e } \\
\text { auxiliares de } \\
\text { enfermagem }\end{array}$ & Atheneu & - & $\begin{array}{l}\text { Fredi, Wanda } \\
\text { Escobar }\end{array}$ & $\begin{array}{l}\text { Rio de } \\
\text { Janeiro }\end{array}$ \\
\hline 1983 & $\begin{array}{l}\text { Amamentação Materna: } \\
\text { incentivo e cuidados. }\end{array}$ & Sarvier & - & $\begin{array}{l}\text { Vinha, Vera H. } \\
\text { Pileggi }\end{array}$ & São Paulo \\
\hline 1983 & $\begin{array}{l}\text { Saúde na escola e na } \\
\text { comunidade }\end{array}$ & Edições Paulinas & - & $\begin{array}{l}\text { Turkiewics, Maria, } \\
\text { Ir. }\end{array}$ & São Paulo \\
\hline 1984 & $\begin{array}{l}\text { Desenvolvimento infantil } \\
\text { em debate }\end{array}$ & - & - & $\begin{array}{l}\text { Benathar, Boberto } \\
\text { Levy org. }\end{array}$ & $\begin{array}{l}\text { Rio de } \\
\text { Janeiro }\end{array}$ \\
\hline 1984 & Crianças e doenção fatal & Sarvier & - & Cruz, Magda et alii & São Paulo \\
\hline 1984 & $\begin{array}{l}\text { Jornada Brasileira de } \\
\text { Enfermagem na saúde } \\
\text { escolar e materno- } \\
\text { infantil. }\end{array}$ & - & - & - & Belém \\
\hline 1984 & $\begin{array}{l}\text { Apostila de enfermagem } \\
\text { pediátrica }\end{array}$ & - & - & $\begin{array}{l}\text { Serviço Nacional } \\
\text { de Aprendizagem } \\
\text { Comercial } \\
\text { Departamento } \\
\text { Regional de Goiás }\end{array}$ & Goiânia \\
\hline 1985 & $\begin{array}{l}\text { Manual de } \\
\text { procedimentos e } \\
\text { organização de } \\
\text { enfermagem em } \\
\text { pediatria. Manual para } \\
\text { atendimento de } \\
\text { enfermagem em } \\
\text { urgências. }\end{array}$ & $\begin{array}{l}\text { Federação das } \\
\text { Misericórdias do } \\
\text { Estado de São } \\
\text { Paulo }\end{array}$ & - & Justo Geraldo & São Paulo \\
\hline
\end{tabular}




\begin{tabular}{|c|c|c|c|c|c|}
\hline 1985 & $\begin{array}{l}\text { Manual de procedimentos } \\
\text { e organização de } \\
\text { enfermagem em pediatria. } \\
\text { Manual para atendimento } \\
\text { de enfermagem em } \\
\text { urgências. }\end{array}$ & $\begin{array}{l}\text { Federação das } \\
\text { Misericórdias do } \\
\text { Estado de São } \\
\text { Paulo }\end{array}$ & - & $\begin{array}{l}\text { Miranda, Maria } \\
\text { Ap. Merino et alii }\end{array}$ & São Paulo \\
\hline 1985 & $\begin{array}{l}\text { Prática de enfermagem: } \\
\text { UTI Neonatal. }\end{array}$ & Atheneu & - & $\begin{array}{l}\text { Nascimento, } \\
\text { Raquel }\end{array}$ & $\begin{array}{l}\text { Rio de } \\
\text { Janeiro }\end{array}$ \\
\hline 1986 & $\begin{array}{l}\text { Manual de Enfermagem } \\
\text { pediátrica }\end{array}$ & $\begin{array}{l}\text { Organização } \\
\text { Andrei }\end{array}$ & $\begin{array}{l}\text { Maria Julieta } \\
\text { Sampaio e } \\
\text { Marilia Viterbo } \\
\text { de Freitas }\end{array}$ & $\begin{array}{l}\text { Bonnemaison } \\
\text { Michele \& Joly, } \\
\text { Christine }\end{array}$ & São Paulo \\
\hline 1986 & $\begin{array}{l}\text { Consulta de enfermagem } \\
\text { no binômio mãe-filho: } \\
\text { análise das consultas de } \\
\text { enfermagem. }\end{array}$ & - & - & $\begin{array}{l}\text { Campedelli, Maria } \\
\text { Coeli }\end{array}$ & São Paulo \\
\hline 1986 & $\begin{array}{l}\text { Auxiliar de enfermagem: } \\
\text { enfermagem para } \\
\text { recuperação da saúde } \\
\text { materno-infantil. }\end{array}$ & $\begin{array}{l}\text { D.c. Luzzato } \\
\text { Editores Ltda. }\end{array}$ & - & $\begin{array}{l}\text { Genz, Gessy } \\
\text { Correa et alii }\end{array}$ & $\begin{array}{l}\text { Porto } \\
\text { Alegre }\end{array}$ \\
\hline 1987 & Puericultura e enfermagem & Cortez & - & $\begin{array}{l}\text { Rocha, Semiramis } \\
\text { M. M. }\end{array}$ & São Paulo \\
\hline $\mathrm{s} / \mathrm{d}$ & $\begin{array}{l}\text { O choro do lactente: } \\
\text { conhecimento das } \\
\text { enfermeiras do Rio Grande } \\
\text { do Norte. }\end{array}$ & $\begin{array}{l}\text { Imprensa da } \\
\text { U.F.R.N. }\end{array}$ & - & $\begin{array}{l}\text { Leite, Daisy Maria } \\
\text { Gonçalves }\end{array}$ & Natal \\
\hline
\end{tabular}

Fonte: CASTRO, I. B. \& BATISTA, S. S. Livros de Enfermagem: Brasil (1916-1988) Rio de Janeiro, ABEn/CEPEn UFRJ. 1989. $149 \mathrm{p}$. 
QUADRO 2 - NÚMERO E PORCENTAGEM DE LIVROS DE ENFERMAGEM SOBRE ASSISTÊNCIA À CRIANÇA EDITADOS NO BRASIL, DE AUTORES NACIONAIS OU ESTRANGEIROS. 1930-1988.

\begin{tabular}{|c|c|c|c|c|c|c|}
\hline \multirow{2}{*}{ Década } & \multicolumn{2}{|c|}{ Autores Nacionais } & \multicolumn{2}{c|}{ Autores Estrangeiros } & \multicolumn{2}{c|}{ TOTAL } \\
\cline { 2 - 7 } & $\mathbf{N}$ & $\mathbf{9}$ & $\mathbf{N}$ & $\mathbf{\%}$ & $\mathbf{N}$ & $\%$ \\
\hline $1930-1939$ & 1 & 2,5 & 1 & 2,5 & 2 & 5,0 \\
\hline $1940-1949$ & 1 & 2,5 & 0 & 0,0 & 1 & 2,5 \\
\hline $1950-1959$ & 2 & 5,0 & 0 & 0,0 & 2 & 5,0 \\
\hline $1960-1969$ & 0 & 0,0 & 0 & 0,0 & 0 & 0,0 \\
\hline $1970-1979$ & 8 & 20,0 & 2 & 5,0 & 10 & 25,0 \\
\hline $1980-1989$ & 21 & 52,5 & 3 & 7,5 & 24 & 60,0 \\
\hline S/d & 1 & 2,5 & 0 & 0,0 & 1 & 2,5 \\
\hline TOTAL & $\mathbf{3 4}$ & $\mathbf{8 5 , 0}$ & $\mathbf{6}$ & $\mathbf{1 5 , 0}$ & $\mathbf{4 0}$ & $\mathbf{1 0 0 , 0}$ \\
\hline
\end{tabular}

Fonte: CASTRO, I. B. \& BATISTA, S. S. Livros de Enfermagem: Brasil (1916-1988) Rio de Janeiro, ABEn/CEPEn UFRJ. 1989. $149 \mathrm{p}$.

Os textos editados podem ser divididos em duas categorias: os prescritivos, que trazem técnicas, normas e regulamentos e os analíticos, que tratam especificamente de um assunto em profundidade. Como exemplo desta segunda categoria, temos VINHA ${ }^{17}$ e CRUZ et al. ${ }^{6}$, ambos escritos por autores brasileiros.

VINHA $^{17}$ tem por objetivo orientar mães como amamentar seus filhos de uma forma natural e espontânea, oferecer meios para as mães resolverem sozinhas certas dificuldades que surgem no período de amamentação, atingir os profissionais de saúde de todos os níveis, ajudando-os na tarefa de educar mães no ato de amamentar. Desenvolve os seguintes típicos: como e o peito e como funciona, cor do leite, como amamentar o bebe, amamentação e hidratação, como a criança suga, como cuidar do peito, rachadura do bico do peito, amamentação e cólica ou dor de barriga, trabalho da mulher fora do lar, outros aspectos da amamentação, a amamentação e o futuro.

Não se detém apenas em aspectos individuais anátomo-clínicos da amamentação, mas coloca com abrangência toda sua experiência de dezoito anos como enfermeira assistindo mães e crianças.

CRUZ et al. ${ }^{6}$ desenvolvem um estudo sobre as necessidades psíquicas e religiosas da criança portadora de doença fatal e da família e a assistência apropriada e individualizada durante todo o processo. Apresentam inicialmente algumas concepções teóricas sobre a 
morte. A seguir, algumas produções, textos e desenhos de crianças sobre a morte sem nenhuma interpretação psicológica, deixando ao leitor a tarefa de compreender o que essas crianças sentem e querem transmitir. Fazem uma revisão bibliográfica sobre assistência psicológica e religiosa e apresentam, no final, a sugestão de um curso básico para assistência a criança portadora de doença fatal e a família.

Os textos caracterizados como prescritivos dirigem-se fundamentalmente a uma clientela específica, atendentes, auxiliares ou alunos de graduação em enfermagem. Alguns resumidos abaixo exemplificam esta classificação.

ROCHA \& PAIM ${ }^{15}$ escrevem para atendentes de enfermagem a descrição de técnicas e tarefas essenciais para sua atuação em enfermarias de pediatria. Os conhecimentos teóricos sucintos estão relacionados a cada procedimento.

AUGUSTO \& NODA ${ }^{4}$ escrevem para enfermeiras pediatras as normas, procedimentos e métodos de trabalho em Unidade de Terapia Intensiva (UTI) com a finalidade de esclarecer os vários aspectos das funções e atribuições da equipe, bem como as regras que regem esse serviço.

ALEXANDER \& BROWN ${ }^{1}$, se propõem a ensinar as enfermeiras os elementos fundamentais do diagnóstico através do exame físico. Cada capítulo do livro está dividido em discussões sobre a importância do exame de uma parte do corpo, revisão anatômica, descrição do método que será adotado no exame e dos instrumentos que serão empregados; processos que devem ser lembrados pela enfermeira ao examinar determinada região do organismo. Os capítulos são dispostos de acordo com a seqüência habitual adotada em uma ficha de registro do exame físico.

A editora MASSON lançou em 1981, a tradução dos "Cahiers de I "Infermière": Cadernos de Enfermagem - Ginecologia, Obstetrícia e Pediatria, destinados principalmente ao aluno de enfermagem. O Caderno de Enfermagem: Pediatria de STEINSCHNEIDER ${ }^{16}$ apresenta-se dividido em capítulos por patologias: neonatal, digestiva, respiratória e assim por diante. Ao final de cada descrição segue uma seção sobre o "Papel da enfermagem diante de..." Exemplo: "0 papel da enfermagem diante dos vômitos do período neonatal, o papel de enfermagem diante de uma onfalocele".

Os textos de PIZZATO \& DA POIAN ${ }^{12}$, "Enfermagem neonatológica" e "Tarefas individuais programadas sobre enfermagem neonatológica ${ }^{13}$ também se dirigem aos alunos de enfermagem. Trazem uma revisão aprofundada da literatura e as vivências profissionais e pessoais das autoras na assistência ao recém-nascido, mais especificamente, em unidades hospitalares.

A partir desta descrição sucinta de alguns textos, exemplificando, pode-se clarear agora a distinção que se fez ente prescritivos e analíticos.

Os denominados prescritivos, amplamente estudados por ALMEIDA \& ROCHA ${ }^{2} \mathrm{e}$ caracterizados como técnicas de enfermagem, tem por pressuposto a normalização do trabalho, com vistas a sua racionalidade e produtividade. Consistem na descrição do 
procedimento de enfermagem a ser executado, especificando também a relação do material utilizado. Organizados para estruturar o saber da enfermagem, desde o início do século XX nos Estados Unidos, sempre estiveram presentes na enfermagem moderna e, através do tempo, incorporam áreas do conhecimento procurando as razões dos procedimentos.

"As técnicas são uma resposta imediata e significativa ao trabalho hospitalar, principalmente quando de sua organização nas primeiras décadas do século nos Estados Unidos. Neste período, o trabalho de enfermagem é todo subdividido e realizado por tarefas e procedimentos, sem centrar-se no paciente, ou seja, um mesmo paciente é assistido por vários elementos da enfermagem, um o auxilia na higiene pessoal, o outro, lhe dá medicação, um outro faz curativo, etc."

Em sua dimensão histórica as técnicas refletem a divisão técnica do trabalho dentro do setor saúde e a subordinação do trabalho manual ao intelectual.

A caracterização dos textos analíticos foi feita por oposição aos prescritivos. Não se dirigem a uma categoria específica da enfermagem e sim a leitores interessados no assunto. Não estabelecem passos a serem seguidos, procedimentos a serem executados, normas e regulamentos. Expõem o assunto e deixam ao leitor a interpretação. Apesar de trazerem, também como os prescritivos, os conceitos das ciências que fundamentam a prática médica individualizada - anatomia, fisiologia, patologia - não se limita a eles, ampliando suas perspectivas, trazendo conceitos da filosofia, de religiões, ou da própria experiência profissional e pessoal.

Esta distinção torna-se bastante significativa quando consideramos, no processo de trabalho em saúde, que a apreensão de nosso objeto de trabalho consiste basicamente na identificação de suas características que permitem a visualização do produto final. O objeto não se impõe naturalmente, mas e identificado a partir de uma intencionalidade que já antevê o produto final do trabalho. Esses produtos são expressões de necessidades concretas e históricas, que variam. Portanto, deve também variar o conhecimento correspondente aos procedimentos que, ao apreenderem o objeto, executam a transformação com vistas ao produto desejado.

"...a medida em que não ha objetos do trabalho senão no trabalho, tais procedimentos apreendem os diversos objetos possíveis de trabalho, ou ainda, em outros termos, produzem-nos para o trabalho ao apreenderem-nos"'.

\section{Considerações finais}

Os textos analíticos abrem para a enfermagem uma perspectiva, ainda que tênue, no complexo universo do processo de trabalho em saúde, de diversificar o cuidado de enfermagem, atendendo com alguma especificidade a clientela. 
Enquanto os textos prescritivos, elaborando procedimentos técnicos para orientar o trabalho, apenas reproduzem os conhecimentos sobre biologia, fisiologia e patologia que orientam a medicina clínica individualizada, estes estudos analíticos abrem novos recortes visualizando no mesmo cliente outras necessidades.

$\mathrm{Na}$ realidade, as técnicas de enfermagem são instrumentos desenvolvidos pela enfermagem para, dentro do processo coletivo de trabalho em saúde, auxiliar na execução do projeto concebido pela medicina anátomo-clínica, recortando a doença como alteração morfológica e/ou funcional do corpo humano. O corpo individual em que ela ocorre é reduzido ao corpo biológico abstrato, subtraído às suas dimensões sociais. A medicina verá, por exemplo, o ato de amamentar como um ato biológico, o mesmo para todas as mães e filhos, excluindo as variações relativas a família, a especificidade da condição da mulher na e, ao trabalho, à classe social.

Os textos classificados como analíticos não chegam a dimensionar estas questões, mas, fugindo a padronização rígida dos procedimentos hospitalares, permitem aos autores colocar a percepção que têm de outras determinações no corpo individual em que realizam o trabalho.

A enfermeira, identificando necessidades através de sua perspectiva, de seu ângulo de visão no processo de trabalho, como as da mãe durante a amamentação e as da equipe de enfermagem que acompanha a criança com doença fatal, procura um novo recorte intelectual, redimensionando a finalidade de seu trabalho.

Como foi referido acima, são poucos os títulos publicados sobre enfermagem pediátrica e dentre estes, apenas seis apresentam um enfoque analítico. Além disso, tratam de assuntos bastante específicos, com contribuições parciais para o conjunto de conhecimento. Aparentemente há uma relação entre a elevação do curso de enfermagem a nível superior e, principalmente, da instituição da pós-graduação em enfermagem no Brasil e o aumento da produção intelectual própria dos enfermeiros, relacionada as necessidades correspondentes a parte do processo de trabalho que executam nas instituições. Provavelmente há até agora maior produção de textos prescritivos porque o trabalho da enfermagem e fragmentado em tarefas, realizadas por diferentes categorias profissionais, predominando no mercado de trabalho os atendentes, que correspondem a aproximadamente $70 \%$ da força de trabalho em enfermagem no Brasil. Normas, técnicas, regulamentos instrumentalizam seu trabalho na medida em que expõem o que fazer e como fazer, ainda que não apresentem as explicações lógicas e científicas de cada ação.

From the apprehension of the knowledge in pediatrics nursing in Brazil, a research was done in a Brazilian historical bibliographic work of references. From an historical perspective nursing it is seen as a social articulate practice, as pan of a collective process of work. The knowledge in this study is considered as an instrument from which man apprehends his working object. Forty tittles were found about how to take 
care of children, from eight per cent of the group of five hundred and four. The proportion was considered very small. The production which was found was classified under two aspects: the prescriptive and the analytical. The prescriptive texts are those related to normalize the work in view of the rationality and to the productivity. The analytical open the possibility and give the means to diversify the nursing assistance particularizing the care and with another aim related to the nursing work.

UNITERMS: Pediatric nursing, knowledge in pediatric nursing.

Para aprehensión del conocimiento en Enfermería Pediátrica en Brasil, se hizo una estadística en obra de referencia bibliografica de Enfermería Brasileira. La posición teórica metodológica adoptada concibe a la Enfermería una perspectiva histórica, parte de un proceso colectivo de trabajo y el saber como instrumental que permite la transformación del objeto en producto deseado, de acuerdo con la finalidad del trabajo imprimiendo racionalidad en el proceso. Fueron encontrados 40 títulos sobre Asistencia al Niño (8\%) en un total de quinientos y cuatro. La producción fue clasificada en prescriptiva y analítica. Prescriptiva, textos que normalizan el trabajo objetivando su racionalidad y productividad. Analítica, abre la posibilidad de diversificar el ciudad de enfermería atendiendo con alguna especificidad la clientela, redimensionando la finalidad del trabajo de Enfermería.

UNITERMOS: Enfermería pediátrica, conocimiento de enfermería pediátrica.

\section{REFERÊNCIAS BIBLIOGRÁFICAS}

01. ALEXANDER, M. M., BROWN, M. S. Diagnóstico na Enfermagem pediátrica. Trad. Joaquim Clemente de Almeida Moura. São Paulo: Andrei, 1978. 280 p.

02. ALMEIDA, M.C.P., ROCHA, J.S.Y. O saber. Enfermagem e sua dimensão. São Paulo: Cortez, 1986. 127 p.

03. ALMEIDA, M.C.P. et al. A situação da Enfermagem nos anos 80. Os desafios da enfermagem para os anos 90. Trabalho apresentado no 41 Congresso Brasileiro de Enfermagem, Florianópolis, 2 a 7 set. 1989.

04. AUGUSTO, M., NODA, M. Enfermagem pediátrica em terapia intensiva. São Paulo: Sarvier, 1978. $68 \mathrm{p}$.

05. CASTRO, I. B., BAPTISTA, S. S. Livros de Enfermagem: Brasil (1916-1988). Rio de Janeiro: ABEn/CEPEn/UFRJ, 1989. 149 p. 
06. CRUZ, M. et al. Crianças e doença fatal: assistência psicorreligiosa. São Paulo: Sarvier, 1984. 80 p.

07. HEGEL, G. W. F. Introdução a história da filosofia. Trad. Antonio Pinto Carvalho. Coimbra: Armênio Amado, 1974. 172 p. (Coleção Studium).

08. hORTA, W. A., CAStellanos, B. E. P. Processo de Enfermagem São Paulo: EPU/EDUSP, 1979.

09. MENDES GONÇALVES, R. B. Tecnologia e organização social das práticas de saúde: características tecnológicas do processo de trabalho na rede estadual de centros de saúde de São Paulo. São Paulo, 399 p. Tese (Doutorado) - Faculdade de Medicina, Universidade de São Paulo, 1986.

10. MENDES GONÇALVES, R. B. Trabalho em saúde e pesquisa: reflexão a propósito das possibilidades e limites da prática de Enfermagem. In: SEMINÁRIO NACIONAL DE PESQUISA EM ENFERMAGEM - PESQUISA E SERVIÇO, 5, Belo Horizonte, 1988. Anais. Belo Horizonte, 1988.

11. NIGHTINGALE, F. Notas sobre Enfermagem: o que é o que não é. Trad. Amália Correa de Carvalho. São Paulo: Cortez, ABEn/CEPEn, 1985. 174 p.

12. PIZZATO, M. G., Da POIAN, V. R. L. Enfermagem neonatológica. Porto Alegre: Ed. UFRGS, 1982. $162 \mathrm{p}$.

13. PIZZATO, M. G., Da POIAN, V. R. L. Tarefas individuais programadas sobre enfermagem neonatológica. Porto Alegre: Ed. UFRGS, 1982.

14. PRADO, J. R. C. Introdução à lógica dialética: notas introdutórias. São Paulo: Brasiliense, 1979. 261 p.

15. ROCHA, D. N., PAIM, L. Enfermagem pediátrica. Brasília: INL/PIRMOMEC, 1972. 89 p. (Coleção atendente de enfermagem, 4).

16. STEINSCHNEIDER, R. Cadernos de Enfermagem: pediatria. Trad. Dilson C. Bontim e Cecília Pecego Coelho. Rio de Janeiro: Masson, 1981. 270 p.

17. VINHA, V. H. P. Amamentação materna: incentivo e cuidados. São Paulo: Sarvier, 1983. $69 \mathrm{p}$. 